\section{TENDA ITINERANTE DE EDUCAÇÃO AMBIENTAL: ESTRATÉGIAS LÚDICAS COMO MEDIADORAS DO ENSINO}

\author{
Itinerant tent for environmental education: playing strategies as mediators of \\ education
}

Tienda itinerante para la educación ambiental: estrategias de juego como mediadores de la educación

\begin{abstract}
Resumo: As cidades arborizadas conseguem promover mais qualidade de vida, conforto e lazer para os seus habitantes. Logo, percebe-se a importância da manutenção das árvores, em especial as nativas, no ambiente urbano. Diante disso, este trabalho teve como objetivo principal sensibilizar ambientalmente a comunidade de Umuarama - PR, em especial quanto à arborização urbana. Para tanto, atividades lúdicas de educação ambiental foram realizadas em ambiente formal e não formal nesta cidade, utilizando-se uma Tenda Itinerante. Ao final desta experiência de extensão, percebeu-se que esta estratégia foi capaz de despertar a participação ativa dos sujeitos, promovendo a reflexão sobre importantes questões ambientais locais. Espera-se que, a partir deste relato, as pessoas sejam sensibilizadas quanto à necessidade da mudança de comportamento em relação à preservação da arborização urbana.
\end{abstract}

Palavras-Chave: Qualidade de vida; arborização urbana; sensibilização ambiental; preservação.

\begin{abstract}
Cities with lots of trees manage to promote more quality of life, comfort and leisure for their habitants. Soon, the importance of maintaining trees, especially native trees, is perceived in the urban environment. Therefore, this work had as main objective to raise environmental awareness in the community of Umuarama - PR, especially regarding urban afforestation. For this, recreational activities of environmental education were carried out in a formal and non-formal environment in this city, using an Itinerant Tent. At the end of this study, it was realized that this strategy was able to awaken the active participation of the people, promoting reflection on important local environmental issues. It is expected that, from this study, people will initiate a behavior change in relation to the preservation of urban afforestation.
\end{abstract}

Keywords: Quality of life; urban afforestation; environmental awareness; preservation.

Resumen: Las ciudades boscosas logran promover una mayor calidad de vida, comodidad y ocio para sus habitantes. Pronto, la importancia de mantener los árboles, especialmente los nativos, se percibe en el entorno urbano. Por lo tanto, este trabajo tuvo como objetivo principal aumentar la conciencia ambiental en la comunidad de Umuarama - PR, especialmente en relación con la forestación urbana. Para ello, se llevaron a cabo actividades recreativas de educación ambiental en un ambiente formal y no formal en esta ciudad, utilizando una Carpa Itinerante. Al final de este estudio, se dio cuenta de que esta estrategia fue capaz de despertar la participación activa de los sujetos, promoviendo la reflexión sobre importantes cuestiones ambientales locales. Se espera que, a partir de este estudio, las personas inicien un cambio de comportamiento en relación con la preservación de la forestación urbana.

Palabras clave: Calidad de vida; forestación urbana; advertencia ambiental; preservación.

\section{AUTORES:}

\section{ADEILSON MOIZÉS DE OLIVEIRA}

ORCID 0000-0001-6496-7593

'Instituto Federal de Educação, Ciência e Tecnologia do Paraná (IFPR)

\section{KETHLEN CORREA DE SOUZA}

ORCID 0000-0003-0421-5810

2Instituto Federal de Educação, Ciência e Tecnologia do Paraná (IFPR)

\section{EDSON VALERIANO GUIMARÃES}

ORCID 0000-0002-6479-2081

IInstituto Federal de Educação, Ciência e Tecnologia do Paraná (IFPR)

PATRÍCIA PEREIRA GOMES

ORCID 0000-0003-3407-1483

${ }^{4}$ Instituto Federal de Educação, Ciência e Tecnologia do Paraná (IFPR)

\section{NORMA BARBADO
ORCID 0000-0002-0562-3958}

Instituto Federal de Educação, Ciência e Tecnologia do Paraná (IFPR)

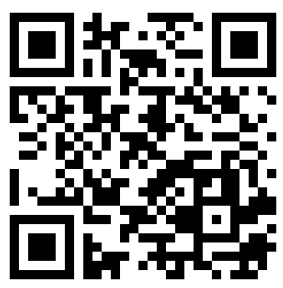

Para citar este artigo:

OLIVEIRA, A. M.; et al. Tenda itinerante de educação ambiental: estratégias lúdicas como mediadoras do ensino. Revista Eletrônica Ludus Scientiae, Foz do Iguaçu, v. 4, n. 2, p. 58-73, 2020. 
INTRODUÇÃO

A constante demanda por recursos naturais decorrentes das atividades antrópicas tem provocado uma série de transformações no planeta, abrindo espaço para graves fatores de degradação ambiental. Desde o século XIX, com a revolução industrial, o ser humano tem deixado o meio rural com destino às cidades, buscando melhores condições de vida. Esse processo migratório promoveu uma urbanização muito rápida e de forma desordenada, sem um planejamento adequado de ocupação (PIVETTA; SILVA FILHO, 2002).

A urbanização modifica a estrutura física e biótica do hábitat, podendo afetar diversos processos ecológicos que envolvem todos os seres vivos nestas áreas (BURN; LINK; BURN, 2007). As inúmeras interferências antrópicas provocaram uma intensa mudança na paisagem, já que árvores são retiradas para dar lugar às residências ou para o desenvolvimento de atividades econômicas (CABRAL, 2013). Nesse sentido, as áreas verdes urbanas, mesmo em pequenas dimensões, além de embelezarem a cidade, contribuem para a manutenção da biodiversidade local, melhoria do clima, controle de pragas e doenças, melhor conforto ambiental, saúde e lazer (PASQUAL; FACHINI, 2008).

O município de Umuarama - PR possui áreas naturais urbanas protegidas, como: Parque Municipal dos Xetá, conhecido como Bosque do Índio, criado pelo decreto municipal o73/1973, com 19,98 ha de extensão; Parque São Francisco de Assis, conhecido como Tucuruvi, criado pela Lei Municipal 2.321/2000, com 28,66 ha de extensão; Bosque Uirapuru, criado pela Companhia Melhoramentos Norte do Paraná, colonizadora desta cidade, em 11 de outubro de 1963 e doado a Prefeitura Municipal de Umuarama em 2010. Essas áreas, apesar de pequenas, são consideradas promotoras de melhor qualidade de vida, encorajando atividades saudáveis ao ar livre e servem como laboratórios vivos, com presença de vida silvestre (PASQUAL; FACHINI, 2008).

Entre as finalidades previstas para criação das áreas de proteção do município, destaca-se a de conciliar a proteção da flora, da fauna e dos demais recursos naturais, de forma a proporcionar aos habitantes lazer, descanso e condições para melhoria na qualidade de vida. Além disso, essas áreas promovem a preservação de ecossistemas naturais de relevância ecológica e beleza cênica, realização de pesquisa científica, com atividades de recreação, Educação Ambiental (EA) e turismo ecológico (UMUARAMA, 2016a; UMUARAMA, 2016b).

No entanto, alguns fatores despertam preocupação quanto à preservação dessas áreas de proteção ambiental, tais como: urbanização intensa, poluição de águas pluviais, esgoto clandestino, descarte inadequado de resíduos, presença de espécies exóticas invasoras, focos de erosão e voçorocas abertas em vários setores (UMUARAMA, 2016a). Assim, a manutenção correta da arborização nas vias urbanas se torna difícil devido à falta de participação da comunidade e ausência de sensibilidade ambiental quanto à importância dos espaços verdes (ALMEIDA; GÊA; SIQUEIRA, 2019).

Nesse sentido, entende-se que a EA se configura como uma importante ferramenta em direção à emergência de novos paradigmas que promovam, por meio da sensibilização, a consciência ecológica e crítica, bem como a emancipação do sujeito. A EA nasce como um processo educativo que conduz a um saber ambiental materializado nos valores éticos e nas regras políticas de convívio social e de mercado (SORRENTINO et al., 2005). Diante da necessidade dessa luta ambiental e social, Streck, Redin e Zitkoski (2010) descrevem o surgimento de um novo paradigma educacional. Segundo os autores, Paulo Freire em seus registros efetuados na obra Pedagogia da Esperança (1994) destacava a importância da Pedagogia do Oprimido (1970) ser convertida em um projeto coletivo. Nessa perspectiva, a criatividade do pensar crítico, na perspectiva freireana, revela como compromisso central a realidade (social, cultural, histórica e política) latino-americana, partindo de fenômenos concretos que constituem a humanidade. Partindo desse universo, surge o desafio dialógico-crítico para a conquista de transformações sociais que propiciam uma vida mais digna. De acordo com Costa e Loureiro (2017), as amplas reflexões de Paulo Freire abrem possibilidades para reflexões sobre a relação sociedade-natureza, partindo de suas teorias do conhecimento e de seu método pedagógico. 
Nesse contexto, a experiência aqui relatada associa a EA a diversas práticas no ensino formal e não formal, não ignorando questões relacionadas aos desafios da EA crítica que, conforme Loureiro e Layrargues (2013), busca, entre vários objetivos, analisar e questionar os conflitos ambientais, desenvolver a autonomia e a liberdade das pessoas e implantar uma transformação mais radical possível, no intuito de minimizar a degradação ambiental e humana. A educação formal é aquela que tem um espaço próprio para ocorrer, ou seja, é institucionalizada e prevê organização curricular; já a educação não formal ocorre a partir da troca de experiências entre os indivíduos, sendo promovida em espaços coletivos não formais (CASCAIS; TÉRAN, 2014). As práticas educativas realizadas em ambientes não formais, contribuem na construção de saberes, à medida que se tem a oportunidade de investigar e problematizar situações cotidianas (FANFA; GUERRA; TEIXEIRA, 2019). Vale ressaltar que a educação não formal, não visa competir ou substituir o ensino formal, ao contrário, ela pode contribuir com a instituição de ensino, com programações específicas que articulam a comunidade e a escola (GOHN, 2011).

Partindo desse pressuposto, esta proposta de extensão, aqui denominada 'Tenda Itinerante', teve como objetivo principal sensibilizar ambientalmente a comunidade de Umuarama - PR, em especial quanto à arborização urbana. Os objetivos secundários foram: promover atividades lúdicas de educação ambiental em ambiente formal e não formal; destacar características principais da vegetação (plantas nativas e exóticas); divulgar a importância da manutenção das áreas preservadas nas cidades como um fator de qualidade ambiental; despertar a reflexão sobre a relação homem-natureza.

\section{MATERIAL E MÉTODOS}

Este trabalho foi realizado no município de Umuarama, na mesorregião noroeste do estado do Paraná, coberto originalmente pela Floresta Estacional Semidecidual, com uma grande diversidade de espécies arbóreas (TAKEDA; BOTARI; BOTARI, 2013). Sua posição geográfica está a 442 metros de altitude, aos $23^{\circ} 45^{\prime} 51^{\prime \prime}$ de latitude sul e a $53^{\circ} 19^{\prime} 6^{\prime \prime}$ de longitude oeste (IPARDES, 2020). A classificação climática da região de acordo com método de Köppen é Cfa, clima subtropical úmido com verão quente. As temperaturas médias no verão são superiores a $25^{\circ} \mathrm{C}$ e no inverno inferiores a $18 \stackrel{\circ}{\circ} \mathrm{C}$, com geadas pouco frequentes. A precipitação pluviométrica anual concentra-se entre 1.400,1 a 1.60o (mm), sendo a maior concentração de chuvas no verão (NITSCHE et al., 2019).

A população de Umuarama é de, aproximadamente, 111.557 habitantes (IBGE, 2019) e o município é considerado uma referência em arborização urbana, possuindo, em média, uma árvore por habitante. Diante dessa relevância, o Instituto Federal do Paraná (IFPR) Campus Umuarama, em parceria com o Conselho Municipal do Meio Ambiente (CMMA) e a Prefeitura Municipal de Umuarama (PMU), desenvolveu a partir de 2015, um projeto de extensão denominado Abraço Ambiental. Este projeto, além de promover um grande abraço no Bosque Uirapuru em comemoração ao Dia da Árvore no Brasil (21 de setembro), promoveu diversas ações de EA no ensino formal e não formal, em vários locais da cidade. Dentre as ações, destacam-se: oficinas de educação ambiental, palestras, distribuição de mudas de árvores nativas, plantio de mudas de árvores nativas e, a partir de 2019, iniciaram-se as atividades da tenda itinerante.

Quanto ao método, optou-se pelo dialético que, segundo Pereira et al. (2020), ocorre na natureza e na sociedade, de forma qualitativa, considerando que os fatos se encontram em um contexto social e as contradições se transcendem, demandando a busca por soluções. Os dados descritivos foram obtidos por meio das seguintes etapas: 1) Levantamento bibliográfico sobre a importância da ludicidade na EA, arborização urbana e árvores nativas da região de Umuarama - PR; 2) Elaboração de atividades lúdicas e interativas de EA, para diferentes faixas etárias, com a temática arborização urbana; 3) Aplicação das atividades lúdicas com a Tenda Itinerante. A análise de dados ocorreu de forma indutiva, conforme recomendam Pereira et al. (2020). 
Para efetivação da proposta, foi necessária a compra de duas tendas dobráveis articuladas $\mathrm{x}$ flex 3 x 3m, duas mesas, oito cadeiras, cola quente, EVA, cartolinas, pincéis, tatame infantil e camisetas com a identificação do projeto. Após a aprovação do CMMA, o material foi obtido com recurso do fundo municipal de meio ambiente, que também financiou bolsas de estudos para acadêmicos da Licenciatura em Ciências Biológicas ao longo do desenvolvimento do trabalho.

Os participantes foram selecionados pensando em aplicação das atividades em diferentes segmentos de ensino formal (educação infantil, ensino fundamental, ensino médio e ensino superior) e em um ambiente não formal. Os locais foram definidos (Creche Aconchego, Colégio Estadual Bento Mossurunga, IFPR Campus Umuarama e Praça Miguel Rossafa), e as atividades lúdicas (Quadro 1) foram apresentadas e desenvolvidas com adaptações para cada faixa etária.

Quadro 1. Atividades lúdicas realizadas na tenda itinerante de educação ambiental, seus objetivos, locais de aplicação e participantes.

\begin{tabular}{|c|c|c|c|}
\hline & & & \\
\hline Atividade Lúdica & Objetivo & Local & Participantes \\
\hline \multirow[t]{2}{*}{$\begin{array}{c}\text { Árvore do } \\
\text { conhecimento }\end{array}$} & \multirow[t]{2}{*}{$\begin{array}{l}\text { Observar o } \\
\text { conhecimento } \\
\text { prévio dos } \\
\text { participantes. }\end{array}$} & $\begin{array}{l}\text { IFPR Campus } \\
\text { Umuarama }\end{array}$ & $\begin{array}{l}\text { Estudantes da Licenciatura em Ciências } \\
\text { Biológicas e do Ensino Médio Integrado. } \\
\text { Estudantes do Ensino Fundamental da } \\
\text { Escola Educare, que visitaram o campus. }\end{array}$ \\
\hline & & $\begin{array}{c}\text { Colégio } \\
\text { Estadual Bento } \\
\text { Mossurunga }\end{array}$ & $\begin{array}{l}\text { Estudantes do } 9^{\circ} \text { ano, Ensino Fundamental } \\
\text { II. }\end{array}$ \\
\hline \multirow[t]{2}{*}{ Jogo de palavras } & \multirow[t]{2}{*}{$\begin{array}{l}\text { Conhecer nomes } \\
\text { populares de árvores } \\
\text { nativas da Mata } \\
\text { Atlântica. }\end{array}$} & $\begin{array}{l}\text { IFPR Campus } \\
\text { Umuarama }\end{array}$ & $\begin{array}{l}\text { Estudantes da Licenciatura em Ciências } \\
\text { Biológicas e do Ensino Médio Integrado. } \\
\text { Estudantes do Ensino Fundamental da } \\
\text { Escola Educare, que visitaram o campus }\end{array}$ \\
\hline & & $\begin{array}{c}\text { Colégio } \\
\text { Estadual Bento } \\
\text { Mossurunga }\end{array}$ & $\begin{array}{l}\text { Estudantes do } 9^{\circ} \text { ano, Ensino Fundamental } \\
\text { II. }\end{array}$ \\
\hline \multirow[t]{2}{*}{$\begin{array}{l}\text { Flora da Mata } \\
\text { Atlântica }\end{array}$} & \multirow{2}{*}{$\begin{array}{l}\text { Classificar árvores } \\
\text { como espécies } \\
\text { nativas da Mata } \\
\text { Atlântica ou } \\
\text { exóticas. }\end{array}$} & $\begin{array}{l}\text { IFPR Campus } \\
\text { Umuarama }\end{array}$ & $\begin{array}{l}\text { Estudantes da Licenciatura em Ciências } \\
\text { Biológicas e do Ensino Médio Integrado. } \\
\text { Estudantes do Ensino Fundamental da } \\
\text { Escola Educare, que visitaram o campus }\end{array}$ \\
\hline & & $\begin{array}{c}\text { Colégio } \\
\text { Estadual Bento } \\
\text { Mossurunga }\end{array}$ & $\begin{array}{l}\text { Estudantes do } 9^{\circ} \text { ano, Ensino Fundamental } \\
\text { II. }\end{array}$ \\
\hline $\begin{array}{l}\text { Teatro: O homem } \\
\text { que não gostava } \\
\text { das árvores }\end{array}$ & $\begin{array}{l}\text { Sensibilizar quanto } \\
\text { à importância da } \\
\text { preservação das } \\
\text { árvores. }\end{array}$ & $\begin{array}{l}\text { Berçário } \\
\text { Aconchego }\end{array}$ & Crianças de 1 a 5 anos. \\
\hline $\begin{array}{c}\text { Contação de } \\
\text { história: O homem } \\
\text { que não gostava } \\
\text { das árvores } \\
\end{array}$ & $\begin{array}{l}\text { Sensibilizar quanto } \\
\text { à importância da } \\
\text { preservação das } \\
\text { árvores. } \\
\end{array}$ & $\begin{array}{l}\text { Praça Miguel } \\
\text { Rossafa }\end{array}$ & Crianças de 4 a 8 anos. \\
\hline
\end{tabular}

Fonte: Autoria Própria.

As metodologias das atividades listadas no Quadro 1, bem como o material utilizado estão descritos a seguir:

\section{- Árvore do Conhecimento}

Essa atividade, aplicada a estudantes do Ensino Fundamental, Médio e Superior, é considerada como uma metodologia de introdução, informal e divertida, com objetivo de observar os conceitos prévios dos participantes (JEOVANINO-SILVA; JEOVANINO-SILVA; CARDOSO, 2019), neste caso, sobre a importância da arborização urbana. Durante essa atividade, houve uma introdução com o relato de todas as etapas do projeto Abraço Ambiental e da relevância da valorização da arborização 
urbana. Em seguida, oportunizou-se a reflexão e o diálogo, partindo de questionamentos aos participantes sobre o conhecimento das áreas de preservação na cidade de Umuarama - PR (Parque Municipal dos Xetá, Parque Municipal São Francisco de Assis e Bosque Uirapuru). Os participantes também foram questionados sobre a relevância desses espaços preservados no meio urbano e quais eram os impactos positivos que eles proporcionam aos moradores.

\section{- Jogo de palavras}

Material: Cartões com letras do alfabeto $(10 \mathrm{x} 10 \mathrm{~cm})$, mesas e cadeiras.

Metodologia: A atividade tem início com a explicação dos conceitos de árvores nativas e exóticas. Os participantes foram divididos em dois grupos, os quais recebiam os cartões com diferentes letras do alfabeto embaralhadas. Em seguida, o nome de uma árvore nativa da Mata Atlântica era citado pelo instrutor. O grupo que montasse a palavra primeiro (Figura 1) contabilizava um ponto. O grupo era considerado vencedor quando atingia 10 pontos.
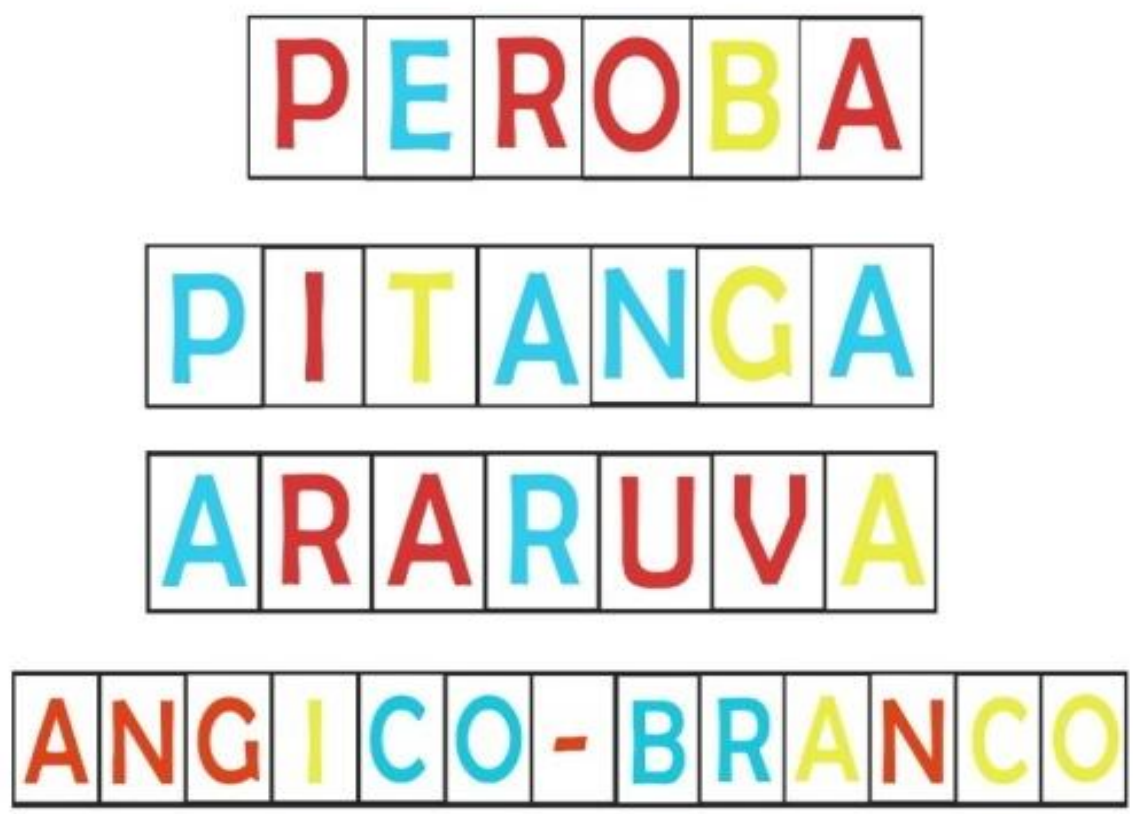

Figura 1: Exemplos de nomes de árvores nativas da Mata Atlântica utilizados na atividade "Jogo de palavras", na Tenda Itinerante de Educação Ambiental. Fonte: Autoria própria.

\section{- Flora da Mata Atlântica}

Material: Papel kraft, 4 troncos de árvore construídos com EVA marrom, recortes de EVA verde em formato de mãos com nomes de árvores nativas da Mata Atlântica e exóticas. Esse material continha fita dupla face no verso.

Metodologia: Os troncos das árvores foram colados no papel kraft. Os participantes foram organizados em 2 grupos. Cada grupo recebeu dois troncos e várias mãos verdes, que representavam as folhas das árvores. Ao sinal do instrutor, os grupos precisavam montar duas árvores: uma era montada com folhas (mãos verdes) que continham nomes de árvores nativas da Mata Atlântica e a segunda era montada com folhas (mãos verdes) contendo nomes de árvores exóticas (Figuras $2 \mathrm{~A}, 2$ B). Ao final da atividade, no pátio da escola, os participantes promoveram um abraço coletivo em árvores, despertando sentimentos de carinho e amor em relação à natureza. 

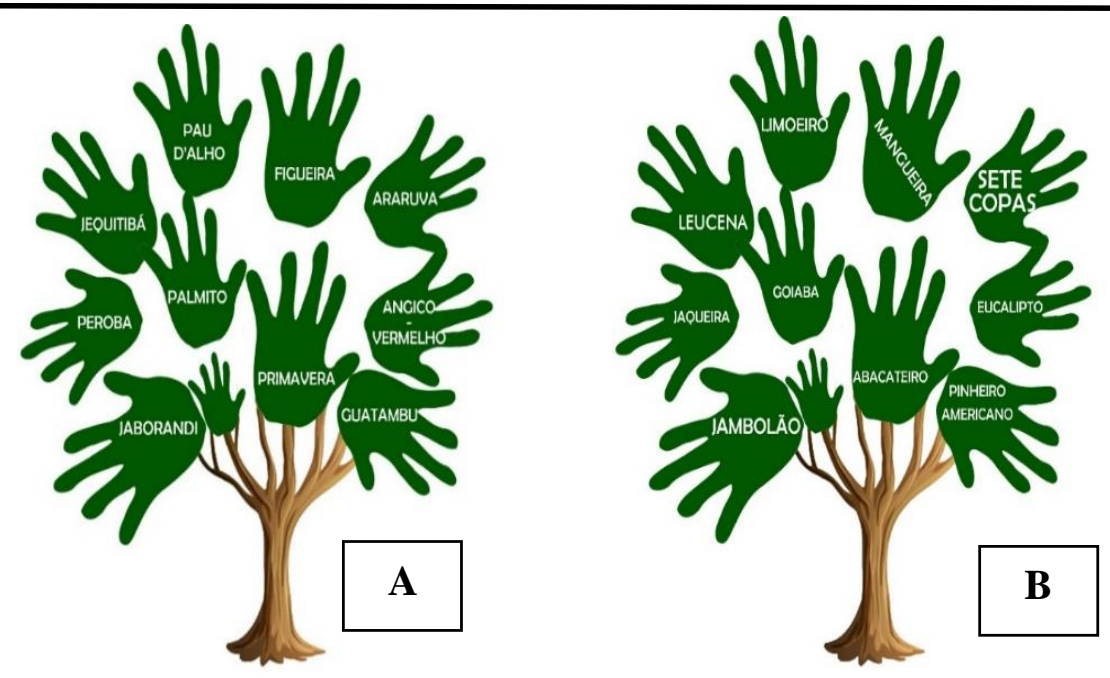

Figura 2: A. Exemplos de nomes de árvores nativas. B. Exemplo de nomes árvores exóticas. Modelos utilizados para montagem no jogo intitulado "Flora da Mata Atlântica”. Fonte: Autoria própria.

\section{- Teatro: $O$ homem que não gostava das árvores}

Material: Tatame infantil colorido, folhas de árvores recolhidas do chão, pessoas simulando árvores, animais de pelúcia e de plástico, machado de brinquedo.

Metodologia: Acadêmicos da Licenciatura em Ciências Biológicas do IFPR Campus Umuarama, voluntários, apresentaram uma peça de teatro intitulada "O homem que não gostava de árvores" (Quadro 2). As crianças assistiram à peça sentadas no tatame infantil. Em seguida, os acadêmicos dialogaram com os participantes visando observar o seu aprendizado sobre a importância da preservação das árvores. Ao final da atividade, as mãozinhas das crianças foram carimbadas com tinta guache verde em papéis, para simular a copa das árvores, auxiliando assim a construção de conhecimento sobre a importância das árvores.

\section{- Contação de história: $O$ homem que não gostava das árvores}

Material: Tatame infantil colorido.

Metodologia: As crianças que estavam brincando no parquinho da praça Miguel Rossafa foram atraídas pelo tatame colorido e se aproximaram para auxiliarem na montagem. Em seguida, sentaramse no tatame e ouviram a história intitulada "O homem que não gostava das árvores" (Quadro 2). Durante a história, as crianças foram questionadas sobre a importância das árvores e da sua preservação. Ao final, as crianças brincaram com o tatame montado em forma de amarelinha.

Quadro 2. História "O homem que não gostava das árvores".

\begin{tabular}{|l|l|l|}
\hline Cena & Personagem & \multicolumn{1}{c|}{ Ação e fala } \\
\hline $\mathbf{1}$ & NARRADOR & $\begin{array}{l}\text { - } \\
\text { também apreciava observar os animais que viviam na mata e beber água da mina. } \\
\text { Porém, esse homem não gostava das árvores, vivia reclamando e com raiva porque } \\
\text { elas deixavam cair suas folhas e sujavam todo o seu quintal. }\end{array}$ \\
\hline $\mathbf{1}$ & $\mathbf{A}$ ÁVORES & $\begin{array}{l}\text { Pessoas vestidas de árvores, com alguns animais de brinquedo amarrados em suas } \\
\text { roupas e com folhas de árvores nas mãos, derrubam as folhas. }\end{array}$ \\
\hline $\mathbf{1}$ & HOMEM & $\begin{array}{l}\text { A personagem resmunga. Em seguida, enquanto varre as folhas, diz: } \\
\text { Eu não aguento mais limpar esse quintal! }\end{array}$ \\
\hline $\mathbf{2}$ & NARRADOR & $-\quad$ Realmente caem muitas folhas das árvores, mas só em algumas épocas do \\
\hline
\end{tabular}




\begin{tabular}{|c|c|c|}
\hline & & $\begin{array}{l}\text { ano. Essas folhas que caem podem servir de adubo para o solo. As árvores servem de } \\
\text { abrigo para muitos animais, produzem frutos, fazem sombra, protegem as nascentes } \\
\text { de água e servem de filtro para os rios. Vocês conhecem algum animal que vive nas } \\
\text { árvores? [Após as respostas, foram citados mais exemplos de animais que não foram } \\
\text { relatados pelas crianças como dependentes das árvores (Ex. Cotia, onça, bicho } \\
\text { preguiça, lagartos arborícolas, insetos, cobras arborícolas, dentre outros)]. } \\
\text { - Muitos animais dependem das árvores direta ou indiretamente para } \\
\text { sobreviver, inclusive os seres humanos. Voltando à história, o homem decidiu que } \\
\text { derrubaria todas as árvores de sua propriedade. Então, ele pegou um machado e toc, } \\
\text { toc, toc, foi cortando uma a uma. }\end{array}$ \\
\hline 2 & HOMEM & $\begin{array}{l}\text { Cortando as árvores com um machado de brinquedo e vendo as árvores caindo ao } \\
\text { chão, diz: } \\
\text { - Agora eu quero ver essas árvores sujarem na minha propriedade! Vai ficar } \\
\text { tudo limpinho nesta terra. }\end{array}$ \\
\hline 2 & ÁRVORES & Rolam e saem de cena à medida que são cortadas. \\
\hline 3 & NARRADOR & $\begin{array}{l}\text { - Depois de um tempo sem árvores, o homem começou a perceber que não } \\
\text { ouvia mais o canto dos pássaros, os animais haviam sumido, a água da mina } \\
\text { também diminuiu e ele começou a sofrer com a falta de água. A natureza que ele } \\
\text { tanto admirava havia ido embora junto com as árvores que ele derrubou. Além } \\
\text { disso, ele passou a sentir muito calor. Foi então que o homem, percebendo o mal } \\
\text { que tinha feito, ficou muito arrependido. }\end{array}$ \\
\hline 3 & HOMEM & $\begin{array}{l}\text { Caminhando triste e com muito calor, procurando os animais, diz: } \\
\text { - E agora? O que tenho que fazer para ter água na mina novamente? Estou } \\
\text { com sede! O que fazer para diminuir esse calor? O que fazer para voltar a ver os } \\
\text { animais e a ouvir o canto dos pássaros que tanto me alegravam? }\end{array}$ \\
\hline 3 & NARRADOR & Foi então que o homem teve uma ideia! \\
\hline 3 & HOMEM & Já sei! Vou plantar as árvores novamente. \\
\hline 4 & NARRADOR & $\begin{array}{l}\text { - E assim ele o fez. Demorou algum tempo para as árvores crescerem e, aos } \\
\text { poucos, os animais foram voltando. A água da mina começou a ficar cristalina } \\
\text { novamente e ele já conseguia ouvir o canto de alguns pássaros. }\end{array}$ \\
\hline 4 & HOMEM & Durante a narração pausada, planta as sementes. \\
\hline 4 & ÁRVORES & Durante a narração pausada, as árvores começam a reaparecer e crescer. \\
\hline 5 & NARRADOR & $\begin{array}{l}\text { Depois desta lição, o homem fez as pazes com as árvores e com a natureza, passou a } \\
\text { aproveitar a sombra e nunca mais reclamou porque as folhas caiam. }\end{array}$ \\
\hline 5 & HOMEM & $\begin{array}{l}\text { Durante a narração pausada, senta na sombra das árvores e descansa sorrindo, } \\
\text { enquanto as folhas caem em cima dele. }\end{array}$ \\
\hline
\end{tabular}

Fonte: Autoria Própria.

\section{RESULTADOS E DISCUSSÃO}

Em todas as atividades lúdicas da Tenda Itinerante de Educação Ambiental (EA), observou-se um grande envolvimento dos participantes. Roloff (2010) relata que a ludicidade pode trazer felicidade e acrescentar leveza à rotina, seja qual for a etapa da vida, propiciando um aprendizado de forma mais significativa. Nesse sentido, Falkembach (2007) enfatiza que toda atividade lúdica que exercite a habilidade mental e a imaginação, ensina com maior eficiência, pois além de transmitir a informação de forma diversificada, estimula diversos sentidos sem que a atividade se torne cansativa.

Durante a aplicação da atividade "Árvore do conhecimento", os participantes puderam expressar, de forma espontânea e divertida, seu prévio conhecimento sobre a importância da 
preservação da arborização urbana. Aconteceram diversos relatos, principalmente na participação de estudantes do Ensino Médio (EM) e do Ensino Fundamental (EF), com citações de nomes de plantas existentes em suas residências, árvores vistas pelo caminho da escola e em viagens já realizadas. Esse conhecimento foi valorizado, considerando-se cada sujeito como um ser social e histórico e, a partir dessa introdução, promoveu-se a autoconfiança dos participantes para uma ação educativa de recriação e ressignificação (FREIRE; HORTON, 2005). Além disso, essa problematização corrobora com o pensamento de Trein (2012) sobre a importância da percepção da relação do homem com a natureza, da construção de conhecimentos sobre a realidade, das leituras de mundo que podem se converter em leituras crítico-reprodutoras ou crítico-transformadoras.

Ainda na "Árvore do Conhecimento", quando os participantes foram questionados se conheciam as áreas de preservação na cidade de Umuarama - PR, percebeu-se que, apesar de saberem da existência dos espaços, poucos já haviam visitado, principalmente o Parque Municipal dos Xetá e o Parque Municipal São Francisco de Assis. Em relação ao Bosque Uirapuru, os estudantes já haviam participado das edições anteriores do projeto Abraço Ambiental (de 2015 a 2019) nesta localidade. Barbado et al. (2016) relatam que dos 343 participantes entrevistados durante a realização do evento em 2015, 74,34\% (225 pessoas) não sabiam o nome comum das árvores do bosque, reforçando a necessidade de ações de educação ambiental para todas as faixas etárias. Assim, o Abraço Ambiental, desde 2015, corrobora com o pensamento de Matos e Maria (2013) quando ilustram que é fundamental uma EA no meio ambiente, em detrimento de uma EA para o ambiente (pensando no lema "agir localmente e pensar globalmente") e sobre o ambiente (com o plantio de mudas de árvores nativas, minimizando os impactos sobre o Bosque Uirapuru).

A divulgação desses espaços para a população é de extrema relevância, já que muitos municípios brasileiros, além de não apresentarem planejamento adequado para arborização, são carentes de áreas verdes (SANTOS et al., 2018). Além disso, percebeu-se a necessidade de desenvolver nos indivíduos as concepções pragmáticas sobre ambiente recomendadas por Sauvé (2005), em que a natureza pode ser vista como recurso, problema, sistema, lugar em que se vive, biosfera e como projeto comunitário.

A respeito da importância desses espaços preservados no meio urbano e seus impactos positivos, tanto no EF quanto no EM, surgiram respostas como "purificação do ar", "embelezamento da cidade", "controle de temperatura" e "lazer da população". No entanto, acadêmicos do Ensino Superior (ES), mais familiarizados com o assunto por estudarem Ciências Biológicas, tiveram respostas mais elaboradas, como "aumento da umidade do ar pela evapotranspiração", "maior controle dos regimes de chuvas", "melhoria da qualidade dos mananciais", "manutenção da biodiversidade" e "produção de oxigênio pela fotossíntese". Sabe-se que a arborização urbana é pauta de muitos debates, tendo em vista sua relevância na qualidade ambiental das cidades e, consequentemente, na qualidade da vida. Como argumenta Pasin (2014), a arborização urbana tem inúmeras utilidades, tais como: purificação do ar pela respiração foliar, sombra para atividades diárias, retenção de impurezas no limbo das folhas, conforto térmico e acústico, retirada de carbono, embelezamento da cidade, entre outros. Cabe destacar, ainda, que a Floresta Atlântica contribui diretamente em vários serviços ambientais, como: regulação do clima, manutenção do ciclo hidrológico, prevenção da erosão do solo, assegurando condições dos recursos ambientais naturais, em especial a biodiversidade e a variabilidade genética (CAMPANILI; SCHAFFER, 2010).

Tais benefícios precisam ser entendidos como prestabilidade pública, reduzindo a dominância de asfalto e concreto, e a consequente impermeabilização do solo, além de garantir beleza às ruas pela inserção de linhas naturais e orgânicas, contribuindo assim para a qualidade ambiental. Pesquisas demonstram que o noroeste paranaense apresenta um quadro de degradação ambiental bastante preocupante, sendo uma das áreas mais degradadas no estado (IPARDES, 2004). Isso ocorreu em consequência direta do intenso desmatamento e da forma inadequada do uso atual e anterior do solo, aliados à vulnerabilidade erosiva dos solos do Arenito Caiuá. Sabe-se que o Noroeste do Paraná já foi todo coberto pela Mata Atlântica. 
No Brasil, restam apenas 16,2 milhões de hectares de florestas nativas preservadas acima de 3 ha na Mata Atlântica. Segundo dados da Fundação SOS Mata Atlântica e do Instituto Nacional de Pesquisas Espaciais (INPE), que monitora este bioma desde 1985, isso corresponde a 12,4\% de sua área original. Entre os 17 estados que possuem Mata Atlântica, nove encontram-se no nível do desmatamento zero, com desflorestamentos abaixo de 100 ha por ano (CE, AL, RN, RJ, ES, PB, PE, SP e SE). Outros três estados estão a caminho desse índice (MS, RS e GO). No entanto, cinco estados ainda mantém os altos índices de desmatamento (MG, PR, PI, BA e SC). Os pesquisadores relatam que, entre 2017 e 2018 no Paraná, 2.049 ha de Mata Atlântica foi desmatada (SOS MATA ATLÂNTICA; INPE, 2019). Essa situação causa impactos diretos na manutenção dos ecossistemas, já que as principais causas da perda de biodiversidade são de origem antrópica, como a destruição e fragmentação do habitat. Acredita-se que nos próximos 30 a 40 anos aproximadamente, $25 \%$ das espécies vegetais existentes no planeta estarão em risco de extinção (CANALE et al., 2012; FERNANDES, 2002).

Outro ponto discutido nesta introdução às atividades da Tenda Itinerante foi a questão da escolha das espécies utilizadas na arborização urbana. Para garantir a segurança e a mobilidade dos usuários dessas áreas, deve-se obedecer a alguns critérios (FARIA; MONTEIRO; FISCH, 2007). Em Umuarama, ainda não foi aprovado o Plano Municipal de Arborização Urbana, o qual encontra-se em processo de construção por membros do CMMA. Além disso, salientou-se que a falta de planejamento e o crescimento desordenado das cidades provocam diversos conflitos, "como a disputa de espaço entre árvores e o espaço das calçadas, a fiação elétrica, os pontos de ônibus e a sinalização de trânsito, entre outros" (SANTOS et al., 2018, p. 27). Todavia, quando há um planejamento correto, a arborização urbana promove a valorização imobiliária, o bem-estar da população e maior conforto térmico (SANTOS et al., 2018). Nessa direção, Avrella, Weiller e Higuchi (2014) também reconhecem os benefícios da arborização urbana para a qualidade de vida das populações, destacando a importância de um planejamento adequado, a fim de evitar problemas que causem interferência nos elementos urbanos e invasão biológica. Diante do exposto, foi reforçado aos participantes da Tenda Itinerante de EA que o bem-estar do homem citadino está vinculado ao componente vegetal que faz parte dos aglomerados urbanos. Assim, plantar árvores nas cidades significa atender à dupla natureza humana: a biológica e a cultural (MALAVASI; MALAVASI, 2001).

Em todos os níveis de ensino (EF, EM e ES), durante o "Jogo de Palavras" observou-se dificuldade no conhecimento das espécies nativas da Mata Atlântica. Porém, após a realização desta atividade lúdica (Figuras $3 \mathrm{~A}, 3 \mathrm{~B}, 4 \mathrm{~A}$ e $4 \mathrm{~B}$ ), percebeu-se que os participantes puderam reconhecer uma lista de espécies nativas. Houve muita interação e pedidos para realização da atividade novamente, já que tinham aprendido os nomes das árvores do jogo. Ainda assim, durante a atividade "Flora da Mata Atlântica" foram observadas diversas dúvidas ao terem que separar por nomes comuns, quais árvores eram nativas deste bioma e quais eram exóticas. Durante a execução dos jogos, observouse competitividade entre as equipes, ficando explícita a vontade de aprender e aplicar o conteúdo. Esse comportamento corrobora com os relatos de Pedrini e Saito (2014) quando citam que o campo teórico está ligado a uma perspectiva mais crítica, em que os indivíduos são percebidos como sujeitos atuantes na transformação do meio ambiente e da sociedade.
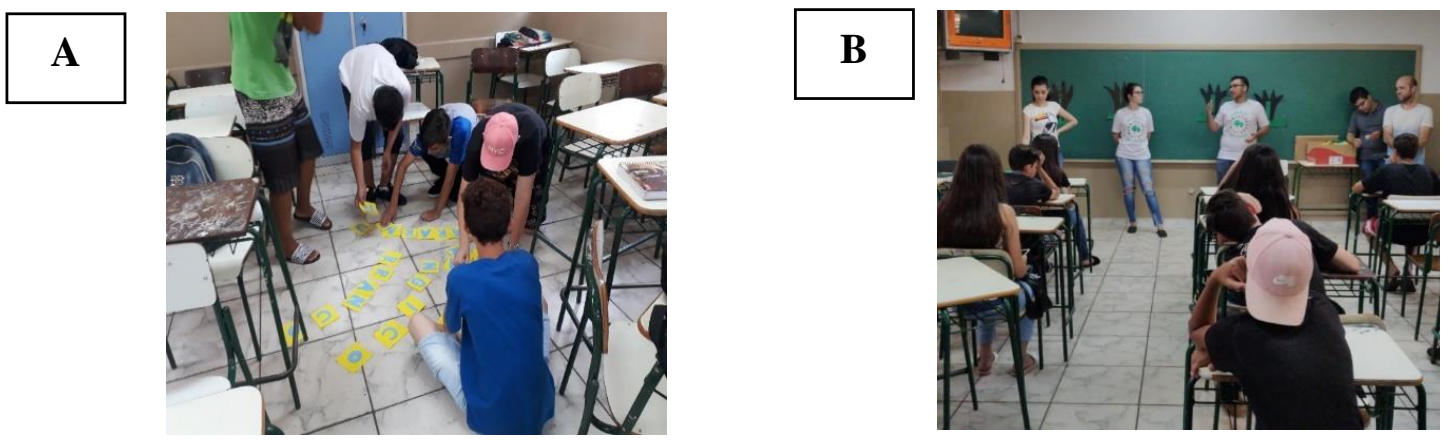

Figura 3: A. Jogo Flora da Mata Atlântica. B. Jogo das Palavras. Atividades realizadas com alunos do ensino fundamental do Colégio Estadual Bento Mossurunga de Umuarama/PR. Fonte: Edson Valeriano Guimarães, para este trabalho. 

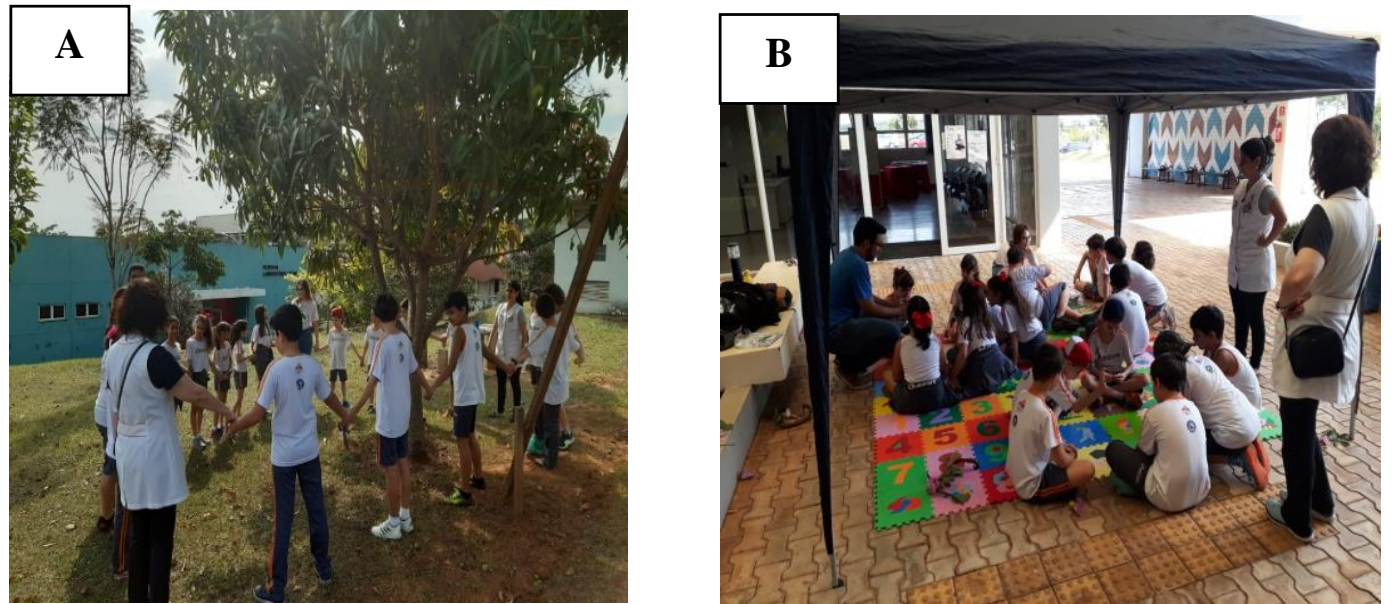

Figura 4: A. Pequeno Abraço Ambiental. B. Jogo das Palavras e Flora da Mata Atlântica. Atividades realizadas na visita dos alunos do ensino fundamental da Escola Educare no Campus do IFPR em Umuarama/PR. Fonte: Edson Valeriano Guimarães, para este trabalho.

Tanto no "Jogo de Palavras" como na atividade "Flora da Mata Atlântica", foram anotadas algumas falas que demonstravam a surpresa dos participantes ao aprender o conceito correto, como por exemplo: "Abacateiro é exótica? Como assim? Eu vi vários pés de abacate no Bosque do Índio!"; "Limoeiro não pode ser uma planta exótica, a cidade está lotada de pés de limão!"; "Quer dizer que esse monte de eucalipto veio tudo de fora?"; "Araruva é uma árvore nativa da Mata Atlântica? Eu nunca ouvi falar esse nome!"; “Existe uma árvore chamada Guatambu? É nativa? Que nome estranho!"; "Eu não vejo pés de Palmito por aqui, tem certeza que é uma árvore nativa da Mata Atlântica?".

Ao final das atividades acima relatadas, foi divulgada a pontuação de cada grupo, bem como a equipe vencedora. Apesar de não haver premiação, a competição foi saudável, buscando demonstrar a relevância de despertar a reflexão e, a partir da troca de experiências, promover a mudança de comportamento. Esse resultado corrobora com a perspectiva crítica da EA, mais consoante com uma proposta transformadora, construtivista e emancipatória na formação do sujeito (RODRIGUES et al., 2019).

Na creche Aconchego, as crianças foram surpreendidas com a apresentação da peça de teatro "O homem que não gostava das árvores" (Quadro 2). A peça foi dirigida e apresentada por acadêmicos da Licenciatura em Ciências Biológicas (Figuras 5 A e 5 B).

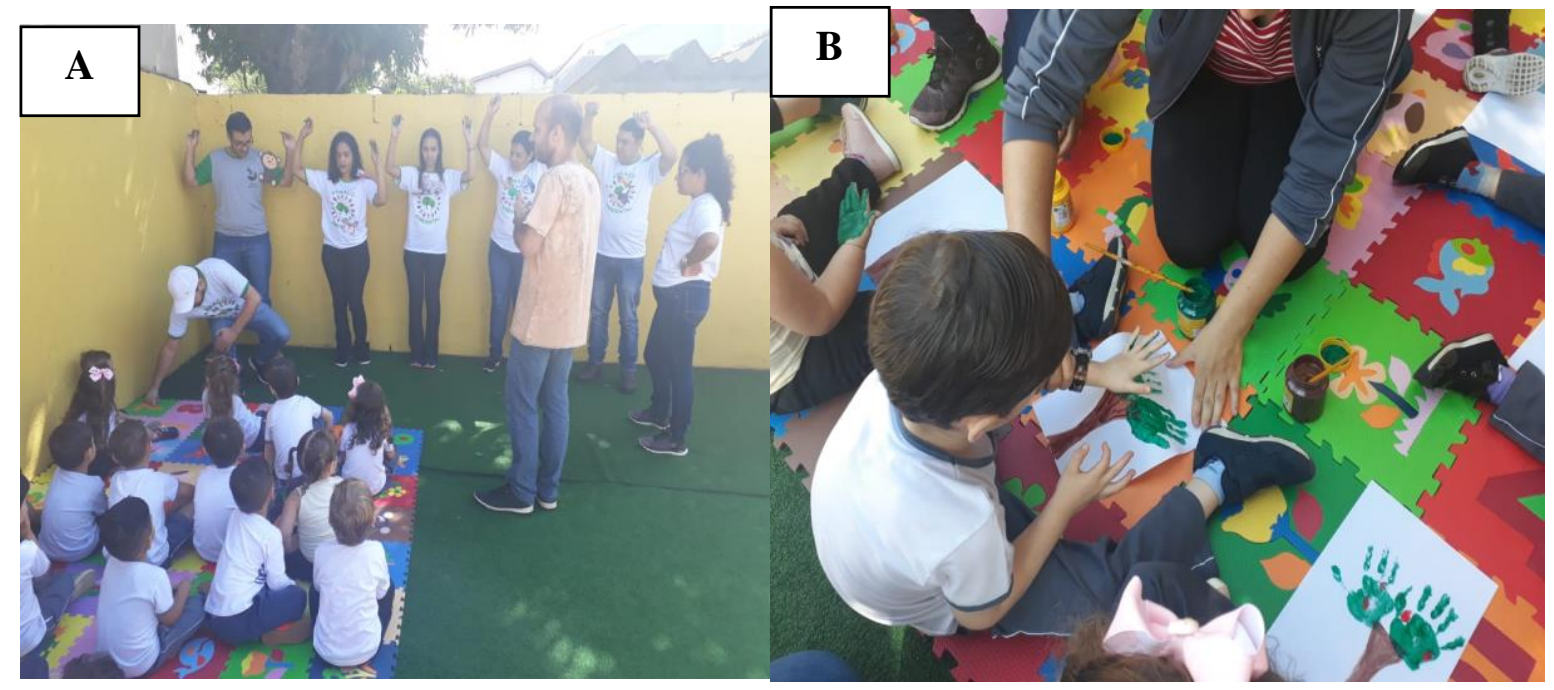

Figura 5: A. Apresentação da peça teatral "O homem que não gostava das árvores”. B. Pintura de árvores com mãos. Atividades realizadas na creche Aconchego de Umuarama/PR. Fonte: Edson Valeriano Guimarães, para este trabalho. 
De acordo com Lummertz e Fischer (2017), apesar de o teatro ter surgido com finalidade cultural, com o passar do tempo foi também adaptado às necessidades sociais. Os autores afirmam que o teatro é uma ferramenta importante da EA, no ensino formal e não formal, com necessidade de adaptações de objetivos e metodologias de acordo com os participantes. Segundo Araújo e Pasquarelli Junior (2007a), o teatro pedagógico tem grande potencial para a implementação da EA em uma perspectiva emancipatória e complexa.

Durante a apresentação da peça, percebeu-se nas crianças muito carinho e amor pela natureza. Houve interação com a história apresentada, exemplos de animais que se relacionam com as árvores foram citados, além de relatarem a importante função das árvores de promover a sombra e embelezar a paisagem. Nesse sentido, ressalta-se a importância de ações de EA com o público infantil, momento em que o sujeito está formando sua personalidade e seus valores, facilitando a mudança de comportamento e atitudes (FISCHER et al., 2018). Algumas falas das crianças foram anotadas: "Mas tio, pra onde os animais foram depois que cortou as árvores?" (nesse momento foi explicado que os animais foram a procura de outro lugar para "morar" e a relação deles com as árvores); "na minha casa tem árvores, mas o meu pai não corta”; “onde os passarinhos vão morar se não tiver as árvores?”; "a árvore faz sombra”. O último comentário foi realizado por uma criança que observou que o teatro estava sendo realizado sob a sombra de uma mangueira localizada no quintal de uma casa vizinha à creche.

Assim como qualquer ferramenta educativa, o teatro apresenta resultado a médio e longo prazo. Dessa forma, o que se pode inferir é que, pela expressão dos espectadores, os objetivos foram alcançados. No entanto, as transformações efetivas só poderão ser percebidas por meio de novas atitudes e mudança de comportamento (ARAÚJO; PASQUARELLI JUNIOR, 2007b). Vale ressaltar que o teatro, sozinho, não pode construir um cidadão consciente. A ação deve ser unida à educação, de responsabilidade da família e da sociedade (MENG; LI, 2014).

Na Praça Miguel Rossafa, em um sábado à tarde, as crianças que estavam brincando no parquinho foram convidadas a participarem de uma atividade da Tenda Itinerante de Educação Ambiental. Após auxiliarem na montagem do tatame infantil, ouviram a história "O homem que não gostava das árvores”, interagiram e contaram suas experiências com as plantas (Figuras 6 A e 6 B). Nesse momento, foi possível identificar os conhecimentos prévios das crianças sobre as árvores e meio ambiente. Reigada e Reis (2004, p. 154), discutindo uma proposta de pesquisa-ação em EA para crianças no ambiente urbano, afirmam que "para garantir a participação da comunidade nas questões ambientais é importante partir da sua concepção de ambiente, para que todo o trabalho tenha sentido, para que os temas abordados e os resultados obtidos sejam significativos e importantes para o grupo".

Depois da história, as crianças brincaram com as mãozinhas verdes que simulavam folhas, com os nomes de árvores nativas da Mata Atlântica e exóticas. Como algumas crianças ainda não eram alfabetizadas, os monitores faziam a leitura dos nomes e explicavam sobre a importância da preservação das árvores, a partir das experiências e conhecimentos prévios das crianças. Ao final da atividade, brincaram de amarelinha de forma divertida e animada, enquanto conversavam sobre o aprendizado adquirido. 


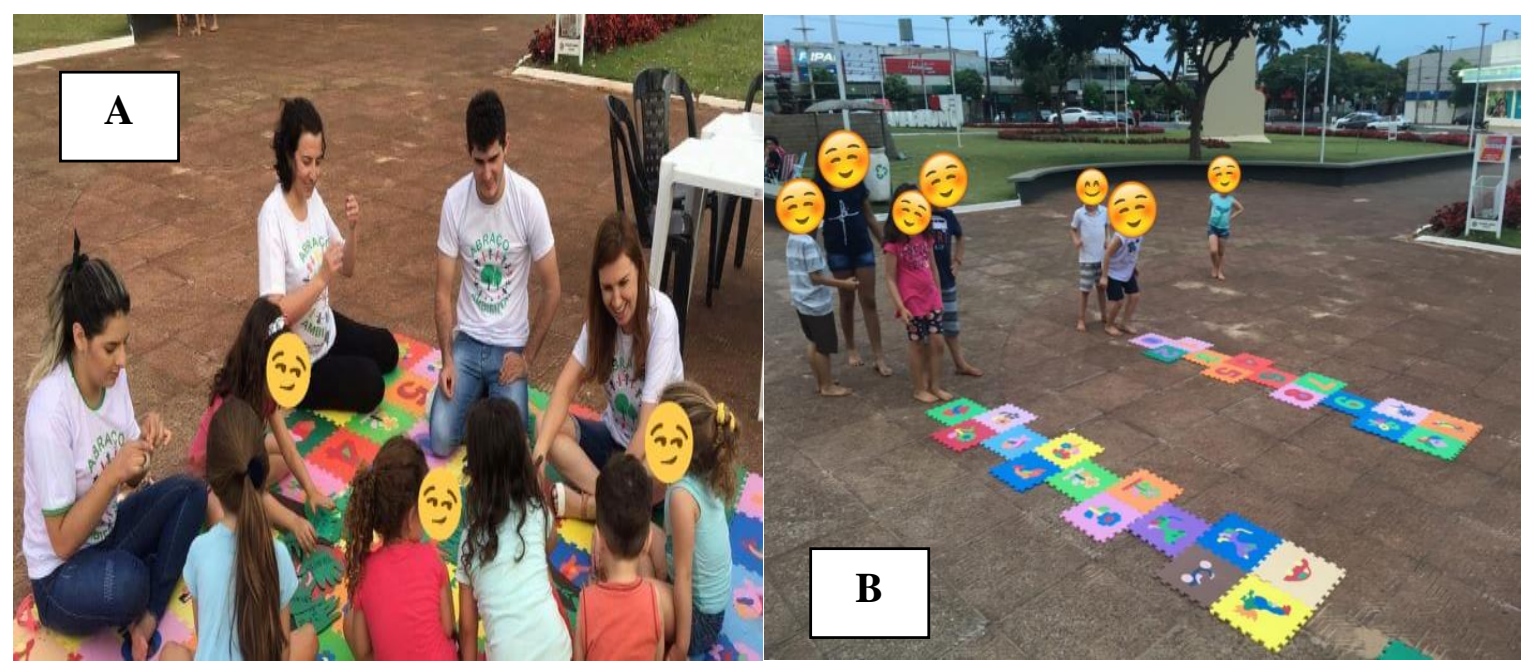

Figura 6: A. Montagem do tatame infantil. B. Jogo "amarelinha”. Atividades realizadas na praça Miguel Rossafa, centro de Umuarama/PR. Fonte: Edson Valeriano Guimarães, para este trabalho.

Em se tratando da abordagem de conceitos de EA com atividades lúdicas na infância, Tristão (2005) relata ser fundamental, pois a sociedade brasileira ainda não resolveu os problemas ambientais mais elementares, dentre eles o desmatamento. A EA com crianças seja em ambiente formal ou não formal contribui, desde cedo, para a construção de valores que encaminhem à consciência ecológica, despertando atitudes e competências voltadas a preservação do meio ambiente. Nesse sentido, Carrega (2009) afirma que, embora a escola seja um ambiente favorável a aprendizagem, estimulando a investigação, descoberta e raciocínio, não se esgotam em sua pedagogia intencional, outras instâncias de socialização dos cidadãos. Pode-se citar como exemplo dessas instâncias: as famílias, os grupos de amigos, instituições de integração não formal, os meios de comunicação de massa que constituem, de igual forma, referência de aprendizagem dos indivíduos.

Não obstante, uma das vantagens do envolvimento precoce em EA, se configura pela aproximação e estreitamento das relações da criança com meio, possibilitando compreender a importância da preservação e de ações sustentáveis para o bem comum. Quando este envolvimento é estimulado e fomentado ao longo do desenvolvimento cognitivo, a sensibilidade pelos temas ambientais e, consequentemente a preocupação com as mudanças nesse cenário serão efetivadas paulatinamente. Esta aproximação da criança ao meio pode ser feita com atividades simples ou projetos devidamente planejados e estruturados, preferencialmente em cenários ao ar livre (PERESTELO, 2017).

Diante do exposto, este trabalho de extensão contribuiu para despertar, em diferentes faixas etárias, a reflexão sobre a importância da preservação da arborização urbana. É também objetivo da EA (re)estabelecer a convivência em grupo, pois para tratar temas complexos, como as questões ambientais é necessário o máximo de informações, resultando em uma visão ampliada do problema. Assim, quanto mais informações, mais próximos da realidade e maior a possibilidade de intervenção, e quanto maior o número de pessoas trabalhando na solução dos problemas, maior a probabilidade de êxito na solução destes (REIGADA; REIS, 2004). Apesar de Umuarama - PR apresentar-se como um exemplo em arborização urbana, nem sempre apresenta condições adequadas de conforto térmico, acústico, luminoso ou visual, conforme recomenda Gonçalves, Camargo e Soares (2012). É fato que a ação antrópica modifica a estrutura da paisagem urbana, muitas vezes com arborização composta de poucas espécies e de forma descontínua (BURN; LINK; BURN, 2007). Assim, é fundamental manter e aumentar o contingente de árvores na cidade, visando minimizar diversos problemas urbanos (GARCIA; BONOTTO, 2017).

Por fim, todas as atividades de extensão realizadas pela Tenda Itinerante, em ambientes formais e não formais, incentivaram a prática de ações sustentáveis, direcionando os participantes a um novo olhar no cenário ambiental da cidade. Esse despertar para os problemas ambientais locais e 
sua interlocução com os problemas globais, abre a possibilidade de emancipação do sujeito a partir da EA (LACET, 2014). Assim, os recursos utilizados nesta proposta foram valiosos para a concretização dos objetivos da EA, pois possibilitaram problematização e discussão crítica das contradições vivenciadas pelos sujeitos, favorecendo a construção de conhecimentos socioambientais (PINTO; BORGES, 2015). Essa criticidade da EA deve ser observada, nos efeitos das ações propostas, nos contextos de compromissos ético-políticos, da produção do conhecimento enquanto produção social, sem se distanciar de sua dimensão ideológica e de seu compromisso de classe (TREIN, 2012).

\section{CONSIDERAÇÕES FINAIS}

A EA é de grande relevância para a formação de cidadãos mais críticos e conscientes de seu lugar no mundo. Em relação à arborização urbana, há poucos relatos de atividades de EA visando sensibilizar a sociedade sobre a importância de sua preservação e do respeito à biodiversidade. Nesse contexto, observou-se que a Tenda Itinerante com atividades lúdicas de EA promoveu sensibilização dos participantes desta proposta. Com participação ativa nos cenários propostos, o processo de aprendizagem tornou-se mais divertido e prazeroso, e as situações vivenciadas nas atividades serviram de problematização para reflexão e debate. Diante disso, acredita-se que a apropriação do conhecimento tenha se tornado mais eficaz, com vistas à mudança de comportamento, efetivando-se assim o processo de EA crítica.

\section{REFERÊNCIAS BIBLIOGRÁFICAS}

ALMEIDA, C. G.; GÊA, B. C. C.; SIQUEIRA, M. V. B. M. Percepção ambiental da população sobre a arborização urbana do bairro centro no município de Arealva, São Paulo. REVSBAU, v.14, n.3, p.37-49, 2019.

ARAÚJO, A. F.; PASQUARELLI JUNIOR, V. Educação Ambiental e teatro: um caminho de pesquisa e ação. In: IV ENCONTRO PESQUISA EM EDUCAÇÃO AMBIENTAL, 2007a, UNESP - RIO CLARO. Anais [...] Rio Claro: IV EPEA, 2007a. Disponível em: http://www.epea.tmp.br/epeazoo7 anais/pdfs/plenary/TR21.pdf. Acesso em 12 mai. 2020.

ARAUJO, A.F.; PASQUARELLI JUNIOR, V. Teatro e Educação Ambiental: um estudo sobre ambiente, expressão estética e emancipação. ReMEA, v. 18, p. 320-335, 2007 b.

AVRELLA, E. D.; WEILLER, E. B.; SILVA, A. C.; HIGUCHI, P. Avaliação quali-quantitativa da arborização urbana de praças e vias públicas. Revista de Ciências Agroveterinárias, v.13, n.3, p. 227-237, 2014.

BARBADO, N.; BASSO, S. E. O.; BELUSSO, D.; RONQUIM, J.; PRAÇA, E. A.; SAKAI, O. A. Abraço Ambiental: Uma experiência de sensibilização sobre a importância da arborização urbana. Revista da Associação Brasileira de Ensino de Biologia. n. 9, p. 2404-2415, 2016.

BRUN, F.G.K.; LINK, D.; BRUN, E.J. O emprego da arborização na manutenção da biodiversidade de fauna em áreas urbanas. REVSBAU, Piracicaba, v.2, n.1, p.117-127, 2007.

CABRAL, P. I. D. Arborização Urbana: Problemas e Benefícios. Revista Especialize On-line, v. 1, n. 6, p. 133-142, 2013.

CAMPANILI, M.; SCHAFFER, W. B. Mata Atlântica: manual de adequação ambiental. Brasília: MMA/SBF, 2010 .

CANALE, G. R..; PERES, C. A.; GUIDORIZZI, C. E.; GATTO, C. A. F.; KIERULFF, C. M. Pervasive defaunation of forest remnants in a tropical biodiversity hotspot. PlosOne, v. 8, n. 7, 1-9, 2012.

CARREGA, M. (2014). Contributos para a Educação Ambiental no Pré-Escolar: Promoção de parcerias comunitárias no planeamento de um projecto de educação não formal a implementar no parque das conchas e dos lilases-lumiar. Dissertação de Mestrado (Programa de Pós-graduação em Ecologia Humana e Problemas Sociais Contemporâneos). Faculdade de Ciências Sociais e Humanas da Universidade Nova.

Lisboa, Portugal, 2014. 
CASCAIS, M. G. A.; TERÁN, A. F. Educação formal, informal e não formal na educação em ciências. Ciência em Tela. v. 7, n. 2, p. 1-10, 2014.

COSTA, C. A.; LOUREIRO, C. F. A interdisciplinaridade em Paulo Freire: aproximações político-pedagógicas para a educação ambiental crítica. Revista Katálysis, v. 20, n. 1, p. 111-121, 2017.

FALKEMBACH, G. A. M. O lúdico e os jogos educacionais. In: Mídias na Educação. CINTED, UFRGS. 2007.

FANFA, M. S.; GUERRA, L.; TEIXEIRA, M. R. F. Educação não formal: a praia como um espaço para educação ambiental. Debates em Educação. Debates em Educação, v. 11, n. 24, p. 67-83, 2019.

FARIA, J. L. G; MONTEIRO, E. A.; FISCH, T. V. Arborização de vias públicas do município de Jacareí - SP. REVSBAU, v. 2, n. 4, p. 20-33, 2007.

FERNANDES, A. Biodiversidade da caatinga. In: ARAÚJO, E. L.; MOURA, A. N.; SAMPAIO, E. V. S.; GESTINARI, L. M. S.; CARNEIRO, J. M. T. Biodiversidade, conservação e uso sustentável da flora do Brasil. Recife: UFRPE/SBB, p. 42-43, 2002.

FISCHER, M. L.; CUNHA, T. R.; MOSER, A. M.; DINIZ, A. L. F. Metodologias inovadoras no ensino da bioética para o curso de Licenciatura em Ciências Biológicas. Revista EDaPECI, v. 18, n. 2, p. 128-142, 2018.

FREIRE, P.; HORTON, M. O caminho se faz caminhando: conversas sobre educação e mudança social. 3. ed. Petrópolis, RJ: Vozes, 2005.

GARCIA, E. S.; BONOTTO, D. M. B. Concepções de munícipes de Rio Claro sobre a arborização urbana. Rev. Eletrônica Mestr. Educ. Ambient. Rio Grande, v. 34, n. 3, p. 112-129, 2017.

GOHN, M. G. Educação não formal e cultura política: impactos sobre o associativismo do terceiro setor. 5ª. ed. São Paulo: Cortez, 2011.

GONÇALVES, A.; CAMARGO, L. S.; SOARES, P. F. Influência da vegetação no conforto térmico urbano: Estudo de caso na cidade de Maringá - Paraná. In: III SEMINÁRIO DE PÓS-GRADUAÇÃO EM ENGENHARIA URBANA, 2012, MARINGÁ. Anais [...] Maringá: III SIMPGEU, 2012. Disponível em: https://pdfs.semanticscholar.org/789o/271cb284edd7e7d66ogage335b1fe1ee5341.pdf . Acesso em: o7 mai. 2020.

INSTITUTO BRASILEIRO DE GEOGRAFIA E ESTATISTICA (IBGE). Panorama. Umuarama - Paraná. 2019. Disponível em: https://cidades.ibge.gov.br/brasil/pr/umuarama/panorama . Acesso em: 13 mai. 2020.

INSTITUTO NACIONAL DE PESQUISAS ESPACIAIS; SOS MATA ATLÂNTICA. São José dos Campos: INPE. Fundação SOS Mata Atlântica e INPE lançam novos dados do Atlas do bioma, 2019. Disponível em: http://www.inpe.br/noticias/noticia.php?Cod_Noticia=5115. Acesso em: 25 mai. 2020.

INSTITUTO PARANAENSE DE DESENVOLVIMENTO ECONÔMICO E SOCIAL (IPARDES). Leituras regionais: Mesorregião Geográfica Noroeste Paranaense. Curitiba: IPARDES: BRDE, 2004. 141p.

INSTITUTO PARANAENSE DE DESENVOLVIMENTO ECONÔMICO E SOCIAL (IPARDES). Caderno estatístico: Município de Umuarama, maio de 2020. 50p. Disponível em:

http://www.ipardes.gov.br/cadernos/MontaCadPdfi.php?Municipio=8750o\&btOk=ok . Acesso em: 07 mai. 2020.

JEOVANINO-SILVA, R. M.; JEOVANINO-SILVA, A. L; CARDOSO, S. P. Guia prático em educação ambiental: sensibilizando de forma crítica, transversal e lúdica. Revista de Educação, Ciências e Matemática, v. 9, n. 2, p. 186-198, 2019.

LACET, A. N. O. Arborização urbana como ferramenta de educação ambiental na Escola Municipal Roberto Simonsen - Campina Grande/PB. Trabalho de Conclusão de Curso. (Graduação em Engenharia Sanitária e Ambiental). Universidade Estadual da Paraíba. Campina Grande, PB, 2014.

LOUREIRO, C.F.B; LAYRARGUES, P. Ecologia Política, Justiça e Educação Ambiental Crítica: perspectivas de aliança contra-hegemônica. Trabalho, Educação e Saúde, v. 11, n. 1, p. 53-71, 2013.

LUMMERTZ, T. B.; FISCHER, M. L. O teatro como ferramenta de promoção de Educação Ambiental. Revbea, V. 12, n. 5, p. 56-72, 2017.

MALAVASI, U. C.; MALAVASI, M. M. Avaliação da arborização urbana pelos residentes - estudo de caso em Mal. Cândido Rondon, Paraná. Ciência Florestal, v.11, n.1, p. 189-193, 2001. 
MATOS, M. S.; MARIA, T. P. Concepções de ambiente em atividades de educação ambiental desenvolvidas em um parque municipal. Revbea, v. 8, n. 1, p. 19-29, 2013.

MENG, X.; LI, S. Study on the Environmental Education of hydraulic engineering. Applied Mechanics and Materials, v. 672-674, p. 2249-2249, 2014.

MORAES, R; GALIAZZI, M. C. Análise Textual Discursiva: Processo reconstrutivo de múltiplas faces.

Ciência \& Educação, v. 12, n. 1, p. 117-128, 2006.

NITSCHE, P. R.; CARAMORI, P. H.; RICCE, W. S.; PINTO, L. F. D. Atlas Climático do Estado do Paraná. Londrina: IAPAR, 2019.

PASIN, A. A. Educação ambiental como ferramenta base da arborização urbana: Desafios da sustentabilidade verde no município de Ibiraiaras - RS. Monografia (Curso de Especialização em Educação Ambiental). Universidade Federal de Santa Maria. Santa Maria, RS, 201

PASQUAL, M. O. A.; FACHINI, M. P. Espaço verde urbano - importância na dinâmica da paisagem. Produção didático-pedagógica do Programa de Desenvolvimento Educacional (PDE). Secretaria de Estado da Educação do Paraná (SEED), 2008. 39p. Disponível em:

http://www.gestaoescolar.diaadia.pr.gov.br/arquivos/file/producoes_pde/md_maria_oliveta_albano_ pasqual.pdf. Acesso em: 25 mai. 2020.

PEDRINI, A.G.; SAITO, C.H. (Org.) Paradigmas metodológicos em educação ambiental. Petrópolis: Vozes, 2014 .

PEREIRA, A. S., SHITSUKA, D. M., PARREIRA, F. J., SHITSUKA, R. (2018). Metodologia da Pesquisa Científica. Santa Maria: UFMS/NTE.

PERESTELO, S. (2017) Concepções de educadores de infância e professores de 1. o ciclo do ensino básico acerca da educação ambiental: Um estudo sobre a importância da educação ambiental. Dissertação de Mestrado (Programa de Pós-graduação em Educação Pré-escolar) Instituto de Educação Superior e Ciências. Lisboa. Portugal, 2017.

PINTO, B.C.T.; BORGES, J.L.C. Uma atividade de educação ambiental em espaço não formal: potencialidades do uso de bacias hidrográficas. Revista Tempos e Espaços em Educação, p. 109-124, 2015.

PIVETTA, K. F. L.; SILVA FILHO, D. F. Arborização urbana. Boletim acadêmico UNESP/FCAV/FUNEP. Série arborização urbana. Jaboticabal: FUNEP, 2002

REIGADA, C.; REIS, M. F. C. T. Educação ambiental para crianças no ambiente urbano: uma proposta de pesquisa-ação. Ciênc. educ. (Bauru). v.10, n.2, p.149-159, 2004.

RODRIGUES, G. S.; PINTO, B. C. T.; FONSECA, L. C. S.; MIRANDA, C. C. O estado da arte das práticas didático-pedagógicas em educação ambiental (período de 2010 a 2017) na revista brasileira de educação ambiental. Revbea, São Paulo, v. 14, n. 1, p. 09-28, 2019.

ROLOFF, E. M. A importância do lúdico em sala de aula. In: SEMANA DE LETRAS, 10, 2010, Porto Alegre. Anais [...] Porto Alegre: PUC, 2010. Disponível em:

https://editora.pucrs.br/anais/Xsemanadeletras/comunicacoes/Eleana-Margarete-Roloff.pdf . Acesso em: 6 maio 2020.

SANTOS, E. P. C. C.; FONTES, L. C.; NASCIMENTO, M. C.; TEIXEIRA, E. K. Arborização urbana na cidade de Ouro Branco/MG: percepção da população e plantio de árvores na comunidade. Revista Compartilhar, v. 2, n. 1, p. 26-28, 2017.

SAUVÉ, L. Educação ambiental: possibilidades e limitações. Educação e Pesquisa, v. 31, n. 2, p. 317-322, 2005 .

SORRENTINO, M.; TRAJBER, R.; MENDONÇA, P.; FERRARO JUNIOR, L. A. Educação ambiental como política pública. Revista Educação e Pesquisa, São Paulo, v. 31, n. 2, p. 285-299, 2005.

STRECK, D; REDIN, Euclides; ZITKOSKI, J. (Orgs.). Dicionário Paulo Freire. Belo Horizonte: Autêntica, 2010 .

TAKEDA, I. J. M.; BOTARI, J. C.; BOTARI, A. Levantamento e caracterização da vegetação de praças representativas do município de Umuarama - PR. In: XIII SAFETY, HEALTH AND ENVIRONMENT 
WORLD CONGRESS, 2013, Porto, Portugal. Anais [...] Porto: XIII SHEWC, 2013. Disponível em:

https://copec.eu/congresses/shewc2013/proc/works/102.pdf . Acesso em: 07 mai. 2020.

TEIXEIRA, N. F. F.; MOURA, P. E. F.; SILVA, F. A. S. A questão do meio ambiente no contexto da globalização: a Educação Ambiental em debate. Revista Equador, v. 5, n. 4, p. 221-234, 2016.

TREIN, E. S. A educação ambiental crítica: crítica de que? Revista Contemporânea de Educação, v. 5, n. 14, p. 304-318, 2012.

TRISTÃO, M. P. Tecendo os fios da educação ambiental: o subjetivo e o coletivo, o pensado e o vivido.

Educação e Pesquisa, São Paulo, v. 31, n. 2, p. 251-264, 2005.

UMUARAMA. Secretaria de Agricultura e Meio Ambiente de Umuarama. ENGETEC: Plano de manejo: Parque Municipal São Francisco de Assis (Tucuruvi), $2016 a$.

UMUARAMA. Secretaria de Agricultura e Meio Ambiente de Umuarama. ENGETEC: Plano de manejo:

Parque Municipal dos Xetá (Bosque do Índio), 2016b.

Adeilson Moizés de Oliveira: Graduando em Ciências Biológicas (licenciatura) pelo Instituto Federal de Educação, Ciência e Tecnologia do Paraná, Campus Umuarama. Participa de projetos de pesquisa e extensão nas áreas de Educação Ambiental, Educação Inclusiva e Ensino de Ciências e Biologia.

E-mail: adeilsonoliveira.cbio@gmail.com

Kethlen Correa de Souza: Graduanda em Ciências Biológicas (licenciatura) pelo Instituto Federal de Educação, Ciência e Tecnologia do Paraná, Campus Umuarama. Foi bolsista do projeto de extensão "Abraço Ambiental" no ano de 2019 financiado pela Prefeitura Municipal de Umuarama (PMU) e Conselho Municipal do Meio Ambiente (CMMA).

E-mail: kethlencorreea@gmail.com

Edson Valeriano Guimarães: Graduando em Ciências Biológicas (licenciatura) pelo Instituto Federal de Educação, Ciência e Tecnologia do Paraná, Campus Umuarama.

E-mail: sondevagui@gmail.com

Patrícia Pereira Gomes: Doutora em Ecologia pela Universidade de Brasilia (UnB). Docente efetiva do Instituto Federal de Educação, Ciência e Tecnologia do Paraná, Campus Umuarama, atuando nos cursos de graduação e mestrado em sustentabilidade (UEM/IFPR).

E-mail: patricia.gomes@ifpr.edu.br

Norma Barbado: Doutora em Agronomia pela Universidade Estadual do Oeste do Paraná (UNIOESTE). Docente do Instituto Federal de Educação, Ciência e Tecnologia do Paraná, Campus Umuarama. Estudante de pós-doutorado do Programa de Pós-Graduação em Geografia (PPGG) da Faculdade de Ciências e Tecnologia (UNESP/FCT).

E-mail: norma.barbado@ifpr.edu.br 